\title{
Pattern of sensitivity to respiratory allergens in patients with sinonasal polyposis
}

\author{
Soheila Nikakhlagh ${ }^{1}$, Farhad Abolnejadian², Nader Saki ${ }^{1}$, Leila Sistani Karmpour ${ }^{3}$
}

\begin{abstract}
Background \& Aim: Sinonasal polyposis is the existence of a nontumoral mass inside the nose and paranasal sinuses which can lead to nasal obstruction and other annoying problems for the patient. Since the pathogenesis of this disease and the involved factors in severity of symptoms has remained unknown, the present study has proceeded to evaluate the Pattern of sensitivity to respiratory allergens in patients with sinonasal polyposis. Methods \& Materials: This observational study was a descriptive cross sectional study evaluating 77 patients with sinonasal polyposis from May 2014 to April 2015. The demographic data, history of signs related to allergy in the patient and his/her family was collected and recorded. The concentrations of serum specific lgE were measured.

Results: Seventy-seven patients with sinonasal polyposis including 25 women (32.5\%) with average age of $42.48 \pm 13.43$ years and 52 men (67.5\%) with average age of $43.40 \pm 13.57$ years were evaluated. The present study showed that the result of allergen test was positive in 32 men (61.54\%) and 20 women (80\%). Also, the results showed that the allergen test was negative in 25 patients (32.47\%), in 6 cases ( $7.79 \%$ ) only one allergen was positive, the results of allergen test in 46 patients (59.74\%), for at least two allergens were positive. The highest numbers of positive allergens in a patient was 28. The most allergen observed in patients included plane tree 23 (29.9\%), Kochia 22 (28.6\%), Alternaria alternaria 20 (26\%), Pigweed 20 (26\%).

Conclusion: Our results indicate that there are correlations between aeroallergen and clinical signs in individuals with sinonasal polyposis, and the possibility of allergic background can be considered in encountering with such patients, although these cases need specific studies with larger sample sizes.
\end{abstract}

Keywords: aeroallergens, sinonasal polyposis, specific $\lg E$

\section{INTRODUCTION}

Sinonasal polyposis is a chronic disorder which influences on life quality of suffering individuals, this disorder is a non-neoplastic inflammation of nose which finally leads to development of abnormal masses in nasal cavity and paranasal sinuses. Treatment of this disorder includes medical treatment, surgery, or combination of these two methods $(1,2)$. Nasal obstruction is the most important sign of sinonasal polyposis which its severity is related to location and size of polyposis, retropharyngeal discharges, headache, anosmia, and coughing are other signs of this disorder (3). Studies have shown that the clinical complications are lower in patients with polyposis in smaller sizes $(4,5)$.

This disease is more common between men comparing to women (ration 2 to 1 ), the average age of nasal polyposis incidence is third and fourth decades of life, although the exact prevalence of this disorder is unknown, but, according to epidemiological studies in various areas of world, it is between 2 to $15 \%$, approximately half of patients with nasal polyposis have a positive family history (6-8).

The pathogenesis of sinonasal polyposis is not accurately determined, but the studies have suggested that different types of infections, immunologic factors, metabolic diseases, congenital diseases such as cystic fibrosis and also autonomic dysfunction are some leading factors of polyposis. From long times ago, the correlation between asthma and

\footnotetext{
Associated Prof of otolaryngology, Hearing research center, Ahvaz Jundishapur university of medical sciences, Ahvaz, Iran.

2 Assistant Prof of Clinical Immunology and allergy, Ahvaz jundishapur university of medical sciences, Ahvaz, Iran.

3 Otolaryngologist, Hearing research center, Ahvaz jundishapur university of medical sciences, Ahvaz, Iran
}

Correspondence: Leila Sistani Karmpou

Otolaryngologist, Hearing research center, Ahvaz jundishapur university of medical sciences, Ahvaz, Iran.

E-mail: Sistani_L@yahoo.com

Received: 26 Aug 2018, Accepted: 22 Oct 2018

(C) 2019 by the authors; licensee Modestum Ltd., UK. This article is an open access article distributed under the terms and conditions of the Creative Commons Attribution License (http://creativecommons.org/licenses/by/4.0/). 
Table 1: Common allergens in Iran

\begin{tabular}{ll}
\hline Mites & Derm.farinae, Derm.pteronssinus \\
\hline Molds & $\begin{array}{l}\text { A.fumigatus, Penicillium expansum, Aspergillus rreus, Penicillium notatum, Aspergillus nidulans, Cladosporium herbarum, } \\
\text { Aspergillus flavus, Alternaria alternaria }\end{array}$ \\
\hline $\begin{array}{l}\text { Animals Epithel And } \\
\text { Feather }\end{array}$ & $\begin{array}{l}\text { Cat epithel, Rodent epithelia, Dog epithel, Rodent epithelia, Rodent epithelia, Rodent epithelia, Doves feather, Goose feather, } \\
\text { Hen feather, Duck feather }\end{array}$ \\
\hline Cockroach & Cockroach mix(P.americana+B.germanica) \\
\hline Trees & Acacia, Olive_Ash mix, Eucaliptus, Olive_Ash mix, Plane tree ( sycamore), Pine mix, Maple, Cypress \\
\hline Weeds & Pigweed, Russian thistle, Chenopdium album, Kochia, Plantain, Orach, Ambrosia, Artemisia, Xanthium, Poplar, Willow, Birch \\
\hline Grasses & Cynodon, Orchard grass, Rye grass, Timothy grass, Kentucky blue, Johnson grass \\
\hline
\end{tabular}

polyposis has been known (9-11). The aim of the present study was to evaluate pattern of sensitivity to respiratory allergens in patients with sinonasal polyposis.

\section{METHODS \& MATERIALS}

This observational study was a descriptive cross sectional study evaluating 77 patients with sinonasal polyposis from May 2014 to April 2015 referring to Ahvaz Imam Hospital. The demographic data, sinonasal symptoms according to SNOT 22 Questionnaire and his/her family history was collected and recorded. The tests based on severity from asymptomatic to very severe ( 0 to $5+)$ in four seasons of spring, summer, autumn and winter were evaluated,

\section{Determination of serum IgE level}

For measurement of IgE specific to studied allergens, 5 mililiters venous blood was collected from the patient and after separation of serum, immediately the serums were frozen at -30 centigrade degree up to day of trial. Commercial kit of AlleisaScreen made by Germany was used according to the kit's guidelines in order to measurement of the amounts of IgE specific to aeroallergens. In this method, the amounts of specific IgE antibody was reported in IU/mI. In Iran, the mentioned standard trial (AllergyScreen ${ }^{\circledR}$ test using common allergens in the country) is Iranized with cooperation of allergiologists and immunologists in the country and Mediwiss company (Germany) (Table 1).

\section{Inclusion and Exclusion Criteria}

The inclusion criteria in the present study were confirmation of polyposis through evaluation of clinical signs and radiologic tests. Patients with cystic fibrosis, kartagener syndrome and fungal allergic sinusitis are excluded from the study.

\section{Statistical Analysis}

After coding, the collected data were analyzed using SPSS software version 18. Qui-square statistical test was used for evaluation of correlation between qualitative variables with each other, and for quantitative variables, $t$-independent test was used. The confidence ratio is $95 \%$ in all measurements and $\mathrm{P}<0.05$ is considered significant.

\section{RESULTS}

\section{Demographic Characteristics of Patients}

In the present study, 77 patients with sinonasal polyposis including 25 women (32.5\%) with average age of $42.48 \pm$ 13.43 years and 52 men (67.5\%) with average age of $43.40 \pm 13.57$ years were evaluated. The ratio of men to women in this study was 2.08 to 1 . There was no significant difference between male and female patients for age. The patients were categorized into two age range of $<40 \& \geq 40$ years, on the other hand, 20 patients (25.97\%) were positive for asthma and 35 patients (45.46\%) had a positive family history and none of them were positive for consumption of NSAIDs sensitivity (Figure 1). 


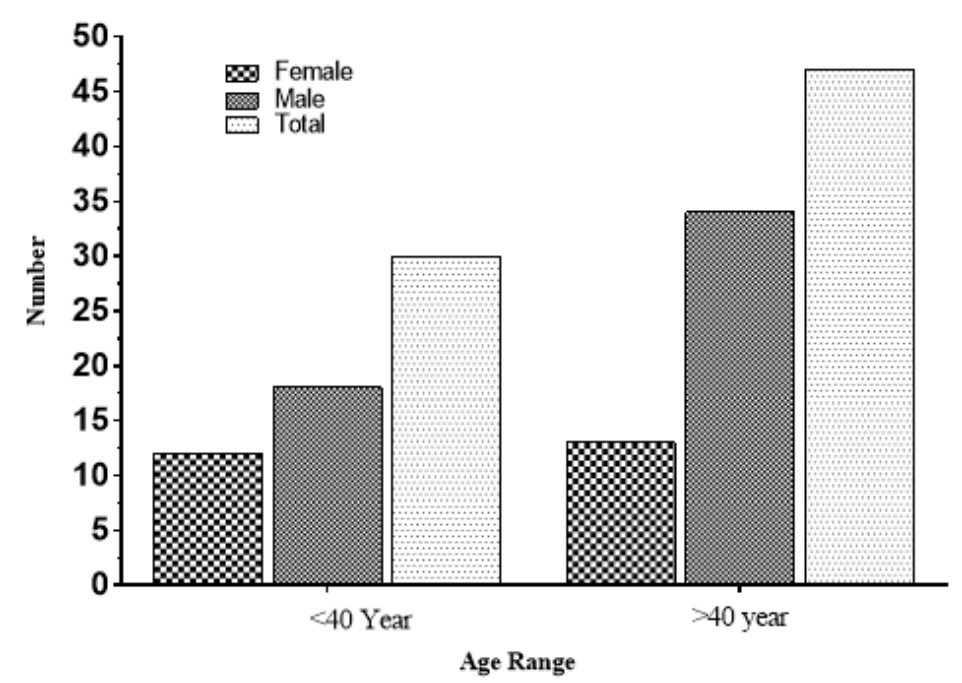

Figure 1: The percentage of evaluated patients based on age categorization

Table 2: The status of studies allergens in patients

\begin{tabular}{|c|c|c|c|c|c|}
\hline \multirow{2}{*}{ Allergen } & \multicolumn{2}{|c|}{ Status } & \multirow{2}{*}{ Allergen } & \multicolumn{2}{|c|}{ Status } \\
\hline & Positive & Negative & & Positive & Negative \\
\hline Derm.farinae & $7(9.1 \%)$ & $70(90.9 \%)$ & Eucaliptus & $16(20.8 \%)$ & $61(79.2 \%)$ \\
\hline Derm.pteronssinus & $12(15.6 \%)$ & 65 (84.4\%) & Olive_Ash mix & $12(15.6 \%)$ & 65 (84.4\%) \\
\hline A.fumigatus & $5(6.5 \%)$ & $62(83.5 \%)$ & Plane tree ( sycamore) & $23(29.9 \%)$ & $54(70.1 \%)$ \\
\hline Penicillium expansum & $8(10.4 \%)$ & $61(89.6 \%)$ & Pine mix & $11(14.3 \%)$ & $66(85.7 \%)$ \\
\hline Aspergillus rreus & $7(9.1 \%)$ & $70(90.9 \%)$ & Maple & $3(3.9 \%)$ & $74(96.1 \%)$ \\
\hline Penicillium notatum & $6(7.8 \%)$ & $71(92.2 \%)$ & Cypress & $2(2.6 \%)$ & 75 (97.4\%) \\
\hline Aspergillus nidulans & $5(6.5 \%)$ & $72(93.5 \%)$ & Poplar & $16(20.8 \%)$ & $61(79.2 \%)$ \\
\hline Cladosporium herbarum & $10(13 \%)$ & $67(87 \%)$ & Willow & $16(20.8 \%)$ & $61(79.2 \%)$ \\
\hline Aspergillus flavus & $5(6.5 \%)$ & $72(93.5 \%)$ & Birch & $18(23.4 \%)$ & $59(76.6 \%)$ \\
\hline Alternaria alternaria & $20(26 \%)$ & 57 (74\%) & Pigweed & $20(26 \%)$ & $50(74 \%)$ \\
\hline Cat epithel & $2(2.6 \%)$ & 75 (97.4\%) & Russian thistle & $18(23.4 \%)$ & $59(76.6 \%)$ \\
\hline Rodent epithelia & $7(9.1 \%)$ & 70 (90.9\%) & Chenopdium album & $17(22.1 \%)$ & $60(77.9 \%)$ \\
\hline Dog epithel & $6(7.8 \%)$ & $71(92.2 \%)$ & Kochia & $22(28.6 \%)$ & $55(71.4 \%)$ \\
\hline Rodent epithelia & $7(9.1 \%)$ & 70 (90.9\%) & Plantain & $13(15.9 \%)$ & 64 (83.1\%) \\
\hline Rodent epithelia & $7(9.1 \%)$ & 70 (90.9\%) & Orach & $18(23.4 \%)$ & 59 (76.6\%) \\
\hline Rodent epithelia & $6(7.8 \%)$ & 71 (92.2\%) & Ambrosia & $0(0 \%)$ & 77 (100\%) \\
\hline Doves & $0(0 \%)$ & 77 (100\%) & Artemisia & $0(0 \%)$ & 77 (100\%) \\
\hline Goose & $0(0 \%)$ & 77 (100\%) & Xanthium & $0(0 \%)$ & $77(100 \%)$ \\
\hline Hen & $0(0 \%)$ & 77 (100\%) & Cynodon & $20(26 \%)$ & $50(74 \%)$ \\
\hline Duck & $0(0 \%)$ & 77 (100\%) & Orchard grass & $12(15.6 \%)$ & 65 (84.4\%) \\
\hline Cockroach mix & $18(23.4 \%)$ & $59(76.6 \%)$ & Rye grass & $13(15.9 \%)$ & $64(83.1 \%)$ \\
\hline Cockroach mix & $18(23.4 \%)$ & 59 (76.6\%) & Timothy grass & $3(3.9 \%)$ & $74(96.1 \%)$ \\
\hline Acacia-mesquite mix & $17(22.1 \%)$ & 60 (77.9\%) & Kentucky blue & $12(15.6 \%)$ & 65 (84.4\%) \\
\hline Acacia-mesquite mix & $16(20.8 \%)$ & $61(79.2 \%)$ & Johnson grass & $3(3.9 \%)$ & $74(96.1 \%)$ \\
\hline Olive_Ash mix & 13 (15.9\%) & 64 (83.1\%) & - & - & - \\
\hline
\end{tabular}

\section{The Status of Allergens in Evaluated Patients}

In the present study, the patients with sinonasal polyposis were evaluated for the presence or absence of respiratory allergens. The results showed that the most frequent observed allergen in patients were: plane tree 23 (29.9\%), Kochia 22(28.6\%), Alternaria alternaria 20 (26\%), pigweed 20 (26\%). On the other hand, the results of Duck, Hen, Artemisisa, Ambrosia, Goose and Xanthium allergens were positive in none of the patients (Table 2).

\section{IgE Specific Concentration}

The mean specific IgE related to respiratory allergens of patients showed that the most amount of this specific antibody were Kochia, Pigweed, Sycamore mix, alternaria alternaria, respectively (Table 3). 
Table 3: The specific concentration of IgE of evaluated antigens

\begin{tabular}{lccc}
\hline Allergen & $\mathbf{I g E}(\mathbf{I U} / \mathbf{m l})$ & Allergen & IgE $(\mathbf{I U} / \mathbf{m l})$ \\
\hline Aspergillus fumigatus & $0.0 \pm 0.0$ & Johnson grass & $0.0339 \pm 0.23$ \\
\hline Aspergillus mix & $0.25 \pm 1.26$ & Kochia & $6.684 \pm 16.78$ \\
\hline Aspergillus nidulans & $0.0 \pm 0.0$ & Kentucky blue & $0.372 \pm 1.32$ \\
\hline Aspergillus rreus & $0.0 \pm 0.0$ & Maple & $0.125 \pm 1.007$ \\
\hline Alternaria alternaria & $2.16 \pm 12.39$ & Olive_Ash mix & $0.923 \pm 3.380$ \\
\hline Aspergillus flavus & $0.0 \pm 0.0$ & Orach & $2.754 \pm 9.558$ \\
\hline Acacia-mesquite mix & $2.14 \pm 7.68$ & Orchard grass & $1.23 \pm 4.27$ \\
\hline Ambrosia & $0.0 \pm 0.0$ & Penicillium notatum & $0.0 \pm 0.0$ \\
\hline Artemisia & $0.0 \pm 0.0$ & Plane tree(sycamore) & $0.88 \pm 3.19$ \\
\hline Bermuda grass & $0.87 \pm 2.94$ & Penicilliumexpansum & $0.0 \pm 0.0$ \\
\hline Birch & $2.02 \pm 8.44$ & Pigweed & $2.98 \pm 12.76$ \\
\hline Cat epithel & $0.08 \pm 0.54$ & Poplar & $0.0 \pm 0.0$ \\
\hline Cladosporium herbarum & $0.33 \pm 1.51$ & Penicillium mix & $0.30 \pm 1.335$ \\
\hline Cockroach mix & Pine mix & $0.66 \pm 2.532$ \\
\hline Cypress & $0.59 \pm 2.34$ & Plantain & $0.49 \pm 1.813$ \\
\hline Cynodon & $0.05 \pm 0.36$ & Russian thistle & $1.25 \pm 4.889$ \\
\hline Chenopdium album & $0.0 \pm 0.0$ & Rye grass & $1.70 \pm 5.096$ \\
\hline Doves & $2.52 \pm 11.26$ & $0.26 \pm 1.308$ \\
\hline Duck & $0.0 \pm 0.0$ & Rodent epithelia & $3.48 \pm 13.85$ \\
\hline Dog epithel & $0.0 \pm 0.0$ & sycamore mix & $0.31 \pm 2.22$ \\
\hline Derm.pteronssinus & Timothy grass & $1.76 \pm 6.28$ \\
\hline Derm.farinae & Willow & $0.0 \pm 0.0$ \\
\hline Eucaliptus & $0.04 \pm 0.17$ & Xanthium & $0.0 \pm 0.0$ \\
\hline Goose & $0.33 \pm 1.28$ & Hen & \\
\hline
\end{tabular}

Table 4: The results of allergen test in patients according to age and gender

\begin{tabular}{ccc}
\hline Parameters & Positive & Negative \\
\hline$<40$ year & $19(63.34 \%)$ & $11(36.66 \%)$ \\
\hline$\geq 40$ year & $33(70.21 \%)$ & $14(29.79 \%)$ \\
\hline Female & $20(80 \%)$ & $5(20 \%)$ \\
\hline Male & $32(61.54 \%)$ & $20(38.46 \%)$ \\
\hline Total & $52(67.53 \%)$ & $25(32.47 \%)$ \\
\hline
\end{tabular}

\section{The Results of Allergen Test According to Age and Gender}

The present study showed that the results of allergen test was positive in 32 men (61.54\%) and 20 women (80\%), also the positive results in age categorization of 40 years old were higher than age categorization younger than 40 years old (Table 4).

\section{The Abundance of Allergens}

The results showed that the allergen tests were negative in 25 patients (32.47\%), in 6 cases (7.79\%) only one allergen was positive, the results of allergen test in 46 patients (59.74\%) was positive for at least two allergens. The most number of positive allergens in a patient was 28 instances (Figure 2). 


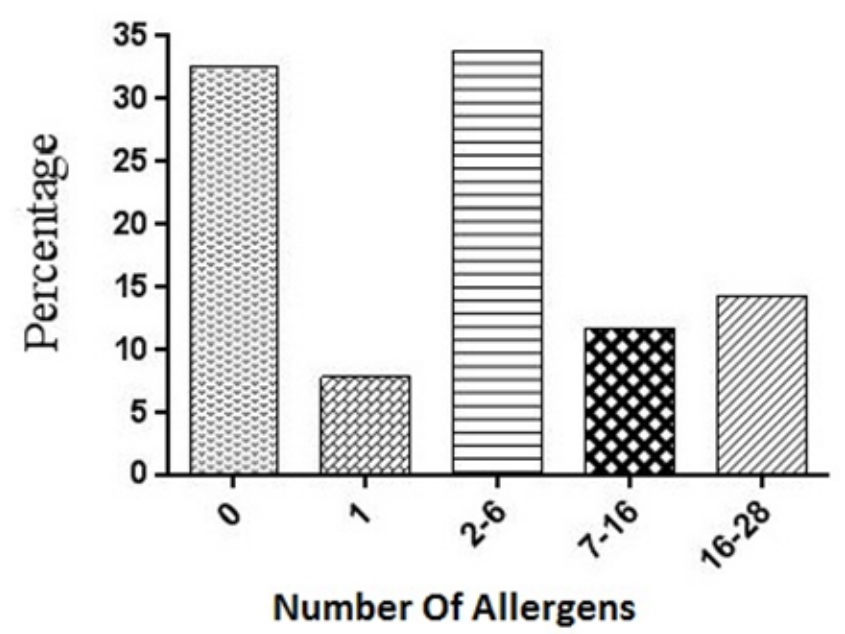

Figure 2: The abundance of evaluated allergens for age and gender

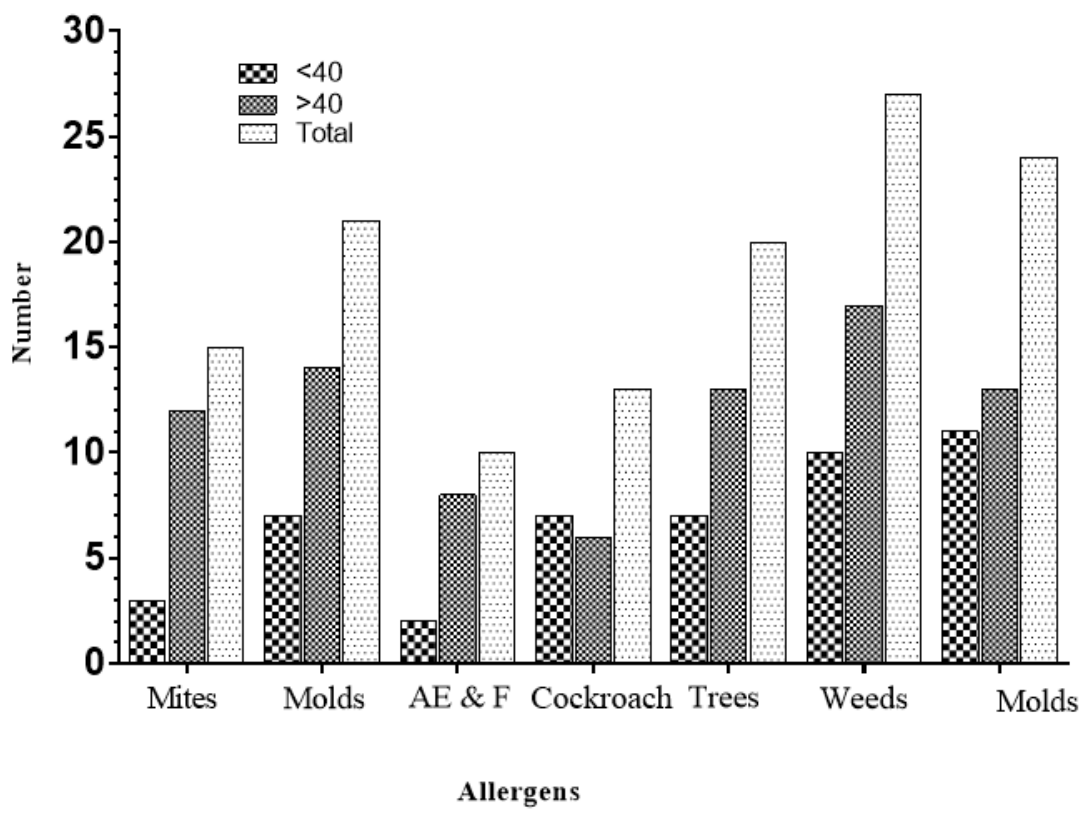

Figure 3: Different types of evaluated allergens for age of patients

\section{The Results Related to Evaluated Allergens}

In the present study, 49 different allergens were evaluated in various categories including mites, molds, epithelium and feather of animals, cockroach, trees, weeds and grasses. The most frequent evaluated allergens were weeds, trees, grasses and ..., respectively (Figure 3).

\section{The Correlation of Allergens and Clinical Signs}

The results showed that there is no significance correlation between clinical signs with age $(P=0.390, r=0.640)$ and gender $(P=0.662, r=0.293)$ of patients. The mean of SNOT in patients was $45.33 \pm 25.11$, on the other hand the results showed that there was an overall significant correlation in facing with molds $(P=0.008, r=0.711)$, cockroach $(P=0.009$, $r=0.816)$, tree $(P=0.028, r=0.673)$, weeds $(P=0.028, r=0.693)$, grasses $(P=0.001, r=0.752)$, but there was no significant correlation between clinical signs and mites $(P=0.217, r=0.666)$. The correlation between allergens and clinical signs are separated shown in Table 5. 
Table 5: The correlation between allergens and clinical signs (separated)

\begin{tabular}{|c|c|c|c|c|c|}
\hline Allergen & Sings & Allergen & Sings & Allergen & Sings \\
\hline \multirow{2}{*}{ Derm.farinae } & $R=0.214$ & \multirow{2}{*}{ Goose feather } & \multirow{2}{*}{-} & \multirow{2}{*}{ Pigweed } & $R=0.454$ \\
\hline & $P=0.062$ & & & & $P=0.000$ \\
\hline \multirow{2}{*}{ Derm.pteronssinus } & $R=0.018$ & \multirow{2}{*}{ Hen feather } & \multirow{2}{*}{-} & \multirow{2}{*}{ Russian thistle } & $R=0.475$ \\
\hline & $P=0.880$ & & & & $P=0.000$ \\
\hline \multirow{2}{*}{ A.fumigatus } & $R=0.040$ & \multirow{2}{*}{ Duck feather } & \multirow[t]{2}{*}{-} & \multirow{2}{*}{ Chenopdium album } & $R=0.496$ \\
\hline & $P=0.733$ & & & & $P=0.000$ \\
\hline \multirow{2}{*}{ Penicillium expansum } & $R=0.217$ & \multirow{2}{*}{ Cockroach mix } & $R=0.441$ & \multirow{2}{*}{ Kochia } & $R=0.406$ \\
\hline & $P=0.058$ & & $P=0.000$ & & $P=0.000$ \\
\hline \multirow{2}{*}{ Aspergillus rreus } & $R=0.010$ & \multirow[t]{2}{*}{ Cockroach } & $R=0.441$ & \multirow{2}{*}{ Plantain } & $R=0.396$ \\
\hline & $P=0.930$ & & $P=0.000$ & & $P=0.000$ \\
\hline \multirow[b]{2}{*}{ Penicillium notatum } & $R=0.307$ & \multirow{2}{*}{ A23 } & $R=0.567$ & \multirow{2}{*}{ Orach } & $R=0.381$ \\
\hline & $P=0.007$ & & $P=0.000$ & & $P=0.001$ \\
\hline \multirow[b]{2}{*}{ Aspergillus nidulans } & $R=0.040$ & \multirow{2}{*}{ A24 } & $R=0.565$ & \multirow{2}{*}{ Ambrosia } & \multirow{2}{*}{. } \\
\hline & $P=0.733$ & & $P=0.000$ & & \\
\hline \multirow{2}{*}{ Cladosporium herbarum } & $R=0.027$ & \multirow{2}{*}{ A25 } & $R=0.497$ & \multirow{2}{*}{ Artemisia } & \multirow[b]{2}{*}{-} \\
\hline & $P=0.815$ & & $P=0.000$ & & \\
\hline & $R=0.028$ & & $R=0.498$ & & \\
\hline Aspergillus flavus & $P=0.806$ & Eucaliptus & $P=0.000$ & Xanthium & - \\
\hline & $R=0.086$ & & $R=0.497$ & & $R=0.491$ \\
\hline Alternarıa alternarıa & $P=0.459$ & Olive_Ash mix & $P=0.000$ & Cynodon & $P=0.000$ \\
\hline & $R=0.088$ & Plane tree & $R=0.437$ & & $R=0.436$ \\
\hline Cat epithel & $P=0.445$ & (sycamore) & $P=0.000$ & Orchard grass & $P=0.000$ \\
\hline & $R=0.058$ & & $R=0.501$ & & $R=0.338$ \\
\hline Rodent epıthelıa & $P=0.618$ & PIne mix & $P=0.000$ & Rye grass & $P=0.003$ \\
\hline & $R=0.113$ & & $R=0.163$ & & $R=0.043$ \\
\hline Dog epithel & $\mathrm{P}=0.328$ & Maple & $P=0.156$ & Timothy grass & $P=0.710$ \\
\hline & $R=0.058$ & & $R=0.276$ & & $R=0.276$ \\
\hline Rodent epithelia & $P=0.618$ & Cypress & $P=0.015$ & Kentucky blue & $P=0.015$ \\
\hline & $R=0.058$ & & $R=0.486$ & & $R=0.019$ \\
\hline Rodent epithelia & $P=0.618$ & Poplar & $P=0.000$ & Johnson grass & $P=0.870$ \\
\hline & $R=0.004$ & & $R=0.486$ & & \\
\hline Rodent epithelia & $P=0.969$ & Willow & $P=0.000$ & & \\
\hline & & & $R=0.427$ & & \\
\hline Doves feather & - & Birch & $P=0.000$ & & \\
\hline
\end{tabular}

\section{DISCUSSION}

In the present study, 77 patients with sinonasal polyposis including 25 women (32.5\%) with average age of $42.48 \pm 13.43$ years and 52 men (67.5\%) with average of $43.40 \pm 13.57$ years were evaluated. More than $70 \%$ of studied patients in this survey were between 40 to 60 years old, epidemiological studies have shown that although the possibility of catching of sinonosal polyposis is present at any age, but with increasing of age, the likelihood of its incidence is increasing and the most prevalent age range for its incidence is 40 to 60 years old, that these reports are consistent with our results $(8,12)$. On the other hand, based on previous reports, the incidence of this study is nearly twofold in men comparing to women $(12,13)$, that this was consistent with our study which showed the ratio of men to women as 2.08 to 1 . On the other hand, 20 patients (25.97\%) were positive for asthma and 35 patients $(45.46 \%)$ had a positive family history of asthma, and none of them were positive for drug consumption. Settipane et al. showed in their study that one third of patients with polyposis, have a history of asthma, that these results were consistent with our results (8).

The results of the present study showed that the most prevalent clinical signs observed in patients -different severitywere: frequent vacant of nose, retropharyngeal discharges, nasal discharge, thick nasal discharge respectively.

Newton et al. (2008) indicated in their review study that the most common clinical sign observed in polyposis patients is nasal obstruction, they also indicated that the severity of obstruction is related to location and size of polyposis (6). Newton et al. (2008) stated that after nasal obstruction, the most frequent signs observed in polyposis patients were nasal discharge and retropharyngeal discharges (6). In study of Ogunleye et al. (2005), 63 patients with polyposis were evaluated and it was shown that the most common clinical signs were nasal obstruction, nasal vacant and sneezing (7). On the other hand, Jahromi et al. (2012) showed that the most prevalent incidence of signs in patients with polyposis 
were in spring and summer seasons (14), the results of the above study was consistent with our results for incidence of clinical signs and season of incidence of these signs.

The present study showed that the results of allergen test were positive in 32 men (61.54\%) and 20 women (80\%), also, the most rate of positive results were at age range of $46-55$. Various studies have reported contradictory results for positive allergen test in patients based on age and gender which some of them were consistent with results of our study and some others were contrast with our results. In study of Shakurnia et al. (2013), the most frequent positive cases were observed at age ranges of 15-35 years old and in male gender (15), although in the present study the most prevalent positive cases were at age range of 46-55 years old and in female gender, the results of the mentioned study were not consistent with results of our study. Kashef and coworkers (2003) showed with evaluation of aeroallergens that the most prevalent positive cases were between individuals older than 15 years old (16), that these results were consistent with our results, there are various reasons reported in results for this difference such as sample size of evaluation, epidemiologic conditions, the rate of exposure of patients, type and size of polyposis.

The results of the present study showed that the results of allergen test were negative in 25 patients (32.47\%), in 6 cases (7.79\%) only one type of allergen was positive, the results of allergen test were positive for at least 2 allergens in 46 patients (59.74\%). The highest number of positive allergens in one patient was 28 cases. On the other hand, the most frequent allergen under evaluation were weeds, trees and grasses, Shakurnia and coworkers (2013) showed that the most prevalent positive cases were related to weeds, trees, mites, fungi and cockroach (15). Also, in study of Assarehzadegan and coworkers (2013) indicated that the most prevalent allergens were weeds, trees, plants pollen, mites and fungi (17). The results of the two above studies were consistent with our results for category of common allergens, the reason for this can be similar climate conditions of two above studies with the present study, because all three studies had been conducted in Ahvaz. However, in a study in shiraz conducted by Kashef et al. (2003) stated in their study that the most prevalent reported allergens were pollen, mites and fungi, respectively (16), that were not consistent with our results, the reason for this can be attributed to different climate status of Ahvaz with Shiraz.

The most identified allergens were Plane tree 23 (29.9\%) Kochia 22 (28.6\%(، Alternaria alternaria 20 (26\%) and Pigweed 20 (26\%), in contrast none of the Goose, Ambrosia, Artemisia, Hen, Duck and Xanthium allergens were detected in the patients. The most positive cases among the weed were Kochia، Pigweed and Russian thistle whereas Assarehzadegan et al have reported Russian thistle as the most common allergen among weed category $(15,17)$. The sample size also the allergen detection methods which have been used in the studies can be reason for the discrepancies; Prick test in previous studies and specific concentration of IgE in the current study.

Alternaria alternaria was the most detected yeast allergen. This specie was also identified as the most prevalent yeast allergen in the previous studies. Intriguingly, Sabirov et al. have shown the significant correlation between the level of IgE serum concentration of Alternaria alternaria and the prevalence of nasal polyp (18).

Derm.pteronssinus and Derm.farinae were positive for $15.6 \%$ and $9.1 \%$ of patients, respectively which are consistent with the results of Kashef et al. who have reported $15.5 \%$ and $12.8 \%$ respectively (16) also Fereidouni et al. have reported the same prevalence as the current study (19) but Assarehzadegan have shown higher positive tests for Derm.farinae than Derm. pteronssinus (17). However, the widespread of this allergen ware higher in Malasia (D. pteronyssinus $93.6 \%$ and D. farina $81.4 \%$ ) (20), Thailand (D. pteronyssinus 76\%, D. farinae 79\%) (21) and Singapore (D. pteronyssinus (93.4\%), D. farinae (92.3\%) (20) than our province. This different is likely related to the growth environmental requirements that are mentioned as $20 \mathrm{C}$ and $60 \%$ humidity for these mites.

The epidermal allergens were positive for $2-7 \%$ of patients whereas Pumhirun have shown 28-35 positive cases in Thailand for those specific allergens (21). The discrepancy can be related to the different methods of animal caring also the various jobs of participants in the studies.

Eucaliptus, Acacia and Olive -Ash were the most prevalent three-associated allergen whereas Assarehzadegan et al. have shown Mesquite, White Ash, Acacia and Eucaliptus as the most common allergen also Pumhirun et al. have indicated that Coconut, mango and acacia produce highest amount of the allergen among all of trees $(17,21)$, however the variation between our study and previous ones can be related to climate features that are necessary for growth of the tree.

The $24.8 \%$ of cases were positive about Cockroach that is consistent with Asarzadegan et al. who also have reported $30 \%$ of positive cases for the allergen but in contrast to Pumhirun et al. that have shown higher than $50 \%$ for positive cases $(12,19)$. This variation likely due to the different climate conditions in Pumhirun et al. study because it was conducted in Thiland where weather conditions are mostly proper for propagating of these beetles than our province. 
The current study has shown Cynodon, Rye grass and Kentucky are the most common allergen in the Grasses group. This prevalence ordering is same as the results of Liam et al. in Malaysia and Assarezadegan although the level of prevalence is in contrast with the last $(17,22)$.

Our study has indicated no correlation between clinical sign and allergen test among 59 patients (76.62\%) however 18 patients (23.38\%) have been found with some level of correlation between clinical signs and allergen level. In the positive group, Grasses cases were most positive cases and then Weeds, Trees, and Mites respectively. Gosepath et al. have determined DNA of some fungus as Alternaria Alternaria in the polyp of patients (23), als Sabirov et al. have indicated the meaningful correlation among pathology of nasal polyps (18) that consistent with our results. Correlation between allergen agents and nasal polyp is considered as a controversial issue. As a temple, Castillo et al. have shown that skin test was significantly higher in patients with nasal polyp than healthy individuals also they have introduced Dermatophagoides pteronyssinus, Dermatophagoides farina and Olea Europaea as the most important polyp-associated allergen (24) also Asero et al. in two different studies have indicated the correlation between polyp and fungal allergen (25). In contrast, Erbek et al. have claimed that there is not any correlation between allergen agents and polyp size also clinical sings and the disease recurrence (26), in addition Bonfils et al. have supported the idea that allergen are not causative agents for nasal polyp (27).

\section{CONCLUSION}

Our results show that some degree of correlation between aeroallergens and clinical signs in patients with sinusoidal polyposis. This type of correlation can be useful in clinical aspect for patient with allergic background although further investigations are needed for confirmation of such correlation.

\section{ACKNOWLEDGEMENTS}

This paper is the result of a resident thesis numbered HRC-95087, registered at the Ahvaz Jundishapur University of Medical Sciences' Ethics Committee with number IR.AJUMS.REC.1395.394. The study was sponsored by University Research Deputy and Hearing Research Center.

\section{REFERENCES}

1. Bachert C, Van Zele T, Gevaert P, De Schrijver L, Van Cauwenberge P. Superantigens and nasal polyps. Current allergy and asthma reports 2003,3:523-31. https://doi.org/10.1007/s11882-003-0065-y PMid:14531975

2. Esmatinia F. Recurrent sinonasal polyposis after the endoscopic sinus surgery. Reviews in Clinical Medicine 2014,1:86-92.

3. Kalpana Kumari M, Mahadeva K. Polypoidal lesions in the nasal cavity. Journal of clinical and diagnostic research: JCDR 2013,7:1040.

4. Wilson KF, McMains C, Orlandi RF. The association between allergy and chronic Rhinosinusitis with and without nasal polyposis: an evidence-based review with recommendations. Int Forum Allergy Rhinol 2014;4:93-103. https://doi.org/10.1002/alr.21258 PMid:24395734

5. Nikakhlagh S, Rahim F, Saki N, Mohammadi H, Maliheh YM (2012) Antrochoanal polyps: report of 94 cases and review the literature. Niger J Med 21(2):156-9. PMid:23311182

6. Newton JR, Ah-See KW. A review of nasal polyposis. Therapeutics and clinical risk management 2008,4:507. https://doi.org/10.2147/TCRM.S2379

7. Ogunleye A, Fasunla A. Nasal polyps-clinical profile and management in Ibadan, Nigeria. Nigerian Journal of Surgical Research 2005,7:164-167.

8. Settipane GA. Epidemiology of nasal polyps. In: Allergy and Asthma Proceedings: OceanSide Publications, Inc; 1996. pp. 231-6. https://doi.org/10.2500/108854196778662246

9. Hulse K, Stevens W, Tan B, Schleimer R. Pathogenesis of nasal polyposis. Clinical \& Experimental Allergy 2015;45:328-46. https://doi.org/10.1111/cea.12472 PMid:25482020 PMCid:PMC4422388

10. Parnes SM, Chuma AV. Acute effects of antileukotrienes on sinonasal polyposis and sinusitis. Ear, nose $\&$ throat journal 2000;79:18. PMid:10665187

11. Fokkens W, Lund V, Mullol J. European position paper on rhinosinusitis and nasal polyps 2007. Rhinology. Supplement 2006:1-136. 
12. Orlandi RR, Kingdom $\mathrm{TT}$, Hwang $\mathrm{PH}$, et al. International consensus statement on allergy and rhinology: rhinosinusitis. Int Forum Allergy Rhinol 2016;6:22-209. https://doi.org/10.1002/alr.21695 PMid:26889651

13. Collins M, Pang YT, Loughran S, Wilson J. Environmental risk factors and gender in nasal polyposis. Clinical Otolaryngology \& Allied Sciences 2002;27:314-7. https://doi.org/10.1046/j.1365-2273.2002.00573.x

14. Ahmad MJ, Ayeh S. The Epidemiological and Clinical Aspects of Nasal Polyps That Require Surgery. Iranian Journal Of Otorhinolaryngology 2012,2:76-7.

15. Shakurnia AH, Assarehzadegan MA, Mozaffari A, Shakerinejad G, Maneshdavi N, Amini A, et al. Prevalence of aeroallergens in allergic patients in Ahvaz. 2013.

16. Kashef S, Kashef MA, Eghtedari F. Prevalence of aeroallergens in allergic rhinitis in Shiraz. Iranian Journal of Allergy, Asthma and Immunology 2003,2:185-8. PMid:17301378

17. Assarehzadegan MA, Shakurnia A, Amini A. The most common aeroallergens in a tropical region in Southwestern Iran. World Allergy Organization Journal 2013;6:7. https://doi.org/10.1186/1939-4551-6-7 PMid:23663517 PMCid:PMC3651228

18. Sabirov A, Hamilton RG, Jacobs JB, Hillman DE, Lebowitz RA, Watts JD. Role of local immunoglobulin E specific for Alternaria alternata in the pathogenesis of nasal polyposis. The Laryngoscope 2008;118:4-9. https://doi.org/10.1097/MLG.0b013e3181567a7a PMid:17989579

19. Fereidouni M, Hossini RF, Azad FJ, Assarezadegan MA, Varasteh A. Skin prick test reactivity to common aeroallergens among allergic rhinitis patients in Iran. Allergologia et immunopathologia 2009;37:73-9. https://doi.org/10.1016/S0301-0546(09)71108-5

20. Nikakhlagh S, Ghafourian-Boroujerdnia M, Saki N, Soltan-Moradi MR, Rahim F. Immunologic factors in patients with chronic polypoid sinusitis. Niger J Med.

$\diamond \diamond \diamond \diamond \diamond \diamond \diamond$

http://www.ejgm.co.uk 